DOE/MT/94003--3

QUARTERLY TECHNICAL PROGRESS REPORT:

ASSISTANCE TO THE STATES

WITH RISK BASED DATA

MANAGEMENT

\title{
INTRODUCTION AND PROJECT DESCRIPTION
}

The following is a quarterly Technical Progress Report of the Risk Based Data Management Systems (RBDMS) project. The project, funded through a United States Department of Energy (DOE) grant is being administered by the Underground Injection Practices Research Foundation (UIPRF) which is the foundation to the Ground Water Protection Council (GWPC).

The Tasks of this project are as follows:

Task I Complete Implementation of a Risk Based Data Management System in the States of Alaska, Mississippi, Montana, and Nebraska.

Task II Conduct Area of Review (AOR) Workshops in the states of California, Oklahoma, Kansas, and Texas.

$\begin{array}{ll}\text { PROJECT STATUS - TASK 1: } & \text { Complete Implementation of a Risk Based } \\ \text { Data Management System in the States of } \\ \text { Alaska, Mississippi, Montana, and Nebraska }\end{array}$

\section{TASK DESCRIPTION}

This project is designed to extend the implementation of a Risk Based Data Management System (RBDMS) in four states. In general this project will assist the states of Alaska, Mississippi, Montana, and Nebraska with converting data from existing data management systems where applicable; coding and internal testing of the RBDMS; preparing documentation, training, and technology transfer; plus project management.

\section{DEVELOPMENT STATUS}

RBDMS is currently in the final stages of development of the system's structure for the first grouping of states including Alaska, Mississippi, Montana, and Nebraska. Intensive testing has taken place during the reporting period. Participating states were provided with the draft final Beta version of the UIPRF's RBDMS in December 1994. 


\section{DISCLAIMER}

Portions of this document may be illegible in electronic image products. Images are produced from the best available original document. 
By early January, 1995 consultants were assisting states with conversions. The system was developed to the point that data conversion was possible yet adjustments to the system's final configuration were still possible. All adjustments were made and the development of the system for this first group of states was completed in late February.

In late February a letter was sent to all of the Oil and Gas State regulatory agencies and representatives of each of the EPA Regions to announce the completion of the final Beta of the RBDMS. The letter encouraged these individuals to attend the March meeting of the GWPC where the only comprehensive, fully relational PC-Based Oil \& Gas regulatory data management system in the country would be demonstrated.

During the GWPC meeting a special session entitled "RBDMS Demonstration and User's Group Meeting" was held. The session was attended by representative of states where RBDMS is being implemented as well as representatives of both state and EPA Regional offices. There was a great deal of interest shown by the participants.

Much of the remaining work completed during this period included assisting the states with training and additional data conversion. Also completed during this period was the development of the RBDMS User's Guide and the RBDMS Administrators Guide.

\section{RBDMS USER'S GUTEE}

During this report period, consultants developed the RBDMS User's Guide and RBDMS Administrators Guide. The User's Guide provides comprehensive information about all functions of the system and includes the indexes and fields for each of the system's modules. Additionally a print out of many of the screens have been included. The RBDMS User's Guide has become useful as an outreach tool for those who are trying to determine if the implementation of RBDMS would be useful for their agency or company.

The RBDMS User's Guide is more than one hundred pages long. Rather than attach the entire document, APPENDIX A contains an overview of the RBDMS User's Guide. If you would like a copy of the entire document, please call 800/762-0190.

\section{RBDMS ADMMNISTRATOR'S GUIDE}

While the User's Guide contains comprehensive information about all the functions of the system the RBDMS Administrator's Guide provides details on hardware and software requirements, installation of RBDMS files, configuration of RBDMS software, RBDMS security setup, and general database information. A copy of the RBDMS Administrator's Guide can be found in APPENDIX B of this report. 


\section{PROJECT STATUS - TASK II: Conduct Area of Review (AOR) Training Seminars}

\section{PROJECT STATUS}

In late 1994 members of UIPRF staff, API, Dr. Warner, as well as, industry representatives met to discuss the details of proceeding with the effort and how it could be coordinated with an API effort with similarities. At this meeting a tentative schedule for four of the workshops was made and included, California in early January-1995, Oklahoma in March-1995, Kansas in May-1995, and Texas date to be determined. Attendees would be invited representatives of the oil and gas and other state agencies that would be involved in developing the state's AOR Variance Plan. In addition, industry would be represented by inviting state oil and gas associations who in turn would send association staff or invite company representatives.

The purpose of these workshops is to acquaint state agency and industry personnel with the AOR variance methodology that has be developed and to seek input from the attendees concerning application of variance methods to injection fields in the state.

The benefits of these workshops are as follows:

- $\quad$ Assist both Direct Implementation and primacy State Class II UIC Directors in establishing workable AOR variance programs.

- Assist operators of both small and large oil and gas producing companies with Class II injection well AOR background and investigative methodologies for conducting AOR's and providing justification for seeking a variance from $A O R$ requirements where applicable.

Each workshop attendee receives a copy of the document developed by a committee of the UIPRF entitled "Technical Criteria for an AOR Variance Methodology. This document includes the background information on UIC program requirements for AOR investigations; general methodologies for performing AOR investigations; data acquisition; alternative methods for evaluating a Class II injection well's AOR; criteria for obtaining exemptions from AOR requirements; and additional, more specific technical and regulatory material. APPENDIX $C$ of this report contains the table of contents and executive summary of the document. If you need a copy of the entire document, please call 800/762-0190. Additional materials specific to each state where the workshops are held are added accordingly.

The California Area-of-Review Workshop was held on January 11, in Bakersfield. The workshop was attended by 33 people including; at least one representative from each of the six California oil and gas state agency district offices and the main office along with representation 
from the California Bureau of Land Management. Industry was also well represented. The California Independent Petroleum Association, the Conservation Committee of California Oil \& Gas Producers, the Western States Petroleum Association, and the Independent Oil Producers' Agency were represented along with several companies including; Mobil, Chevron, Exxon, Shell, Texaco, AMOCO and Cal Resources.

Enclosed you will find a list of the attendees along with the final agenda. Workshop organizers were pleased with the communication that took place and are optimistic that the effort being made by, GWPC, DOE and API will be beneficial to both the State agencies and the oil and gas industry of California.

A list of attendees and the final agenda for the California AOR workshop can be found in APPENDIX D of this report.

The Oklahoma AOR Workshop was held on March 22 in Oklahoma City. This workshop was similarly attended both by number and type of participants as the California workshop. The Oklahoma workshop attendees were asked to fill out evaluation forms. The response was favorable. APPENDIX E contains the agenda, list of attendees and the evaluation form for the Oklahoma workshop.

\section{SUMMARY}

* Project consultants have completed the design and installation of the only comprehensive, fully relational PC-Based Oil \& Gas regulatory data management system (the Risk Based Data Management System) in the country. The implementation is complete in the states of Alaska, Mississippi, Montana, and Nebraska. Training and data conversion are ongoing. During the report period, the RBDMS User's Guide and the RBDMS Administrator's Guide were completed.

* The Area-Of-Review (AOR) workshop series has begun with workshops having been completed in California and Oklahoma during the reporting period.

\section{DISCLAIMER}

This report was prepared as an account of work sponsored by an agency of the United States Government. Neither the United States Government nor any agency thereof, nor any of their employees, makes any warranty, express or implied, or assumes any legal liability or responsibility for the accuracy, completeness, or usefulness of any information, apparatus, product, or process disclosed, or represents that its use would not infringe privately owned rights. Reference herein to any specific commercial product, process, or service by trade name, trademark, manufacturer, or otherwise does not necessarily constitute or imply its endorsement, recommendation, or favoring by the United States Government or any agency thereof. The views and opinions of authors expressed herein do not necessarily state or reflect those of the United States Government or any agency thereof. 


\title{
APPENDIX A
}

\section{Risk Based Data Management System User's Guide}

\author{
version 4.0
}

\section{OVERVIEW}




\section{Risk Based Data Management System User's Guide}

\section{Overview}

The RBDMS Users Manual has been broken down into four parts. These parts include (1) System Documentation (or Help Manual); (2) Screen Captures and Descriptions; (3) RBDMS Codes Table; and (4) Select Standard Reports. The intent of the Users Manual is to introduce the user to the multitude of options available in the system.

The first part of the Users Manual, System Documentation, is a compilation of the RBDMS On-Line Help system and includes descriptions of forms and reports, definitions, and the RBDMS Data Dictionary (i.e., listing of all data fields included in RBDMS). The System Documentation section is broken into three different sub-sections. The first subsection "Overview", gives the user an introduction to the API Numbering Criteria as well as introduction to the Well Selection Criteria Screen, which is the main control screen ir: RBDMS, and the Record Selection Screen, which is used to sort data records through out the RBDMS program. The next sub-section, "Forms", introduces the user to each of the different data entry/inquiry forms used in RBDMS. The last section, "Reports", provides details on all standard reports included in RBDMS and gives details to the user on generating reports from the RBDMS program. Included with the manual is an Appendix showing an index on the data entry fields available in the program.

The Screen Captures Section contains actual snapshots of the RBDMS screens (i.e., forms) that users will view while manipulating the system and for data analysis. There are an assortment of snapshots presented in this section, including those of the cutomized RBDMS menus system, RBDMS custom utilities, and RBDMS special features. These snapshots should provide the user with a means to quickly review all the various modules of the RBDMS as a means of becoming familiar with the program.

A listing of the basic codes and code definitions currently loaded into the RBDMS program are presented in the Codes Table Section. In this section are the standardized codes listings on various data entries ranging from AAPG Basins to Casing Grades. As states add codes, print outs of up-to-date codes should probably be made to replace this section.

In the section on select standard reports, example reports generated by the RBDMS from a set of "Dummy" data are presented. Included in this section are some of the reports that may be used most frequently by states. The intent of this section is simply to provide users with some examples of standard RBDMS reports, the types of outputs the system provides, and the general layout of many of the more frequently used reports. This section does not include all standard RBDMS reports. 


\title{
APPENDIX B
}

\section{Risk Based Data Management System Administrator's Guide}

\author{
version 4.0
}




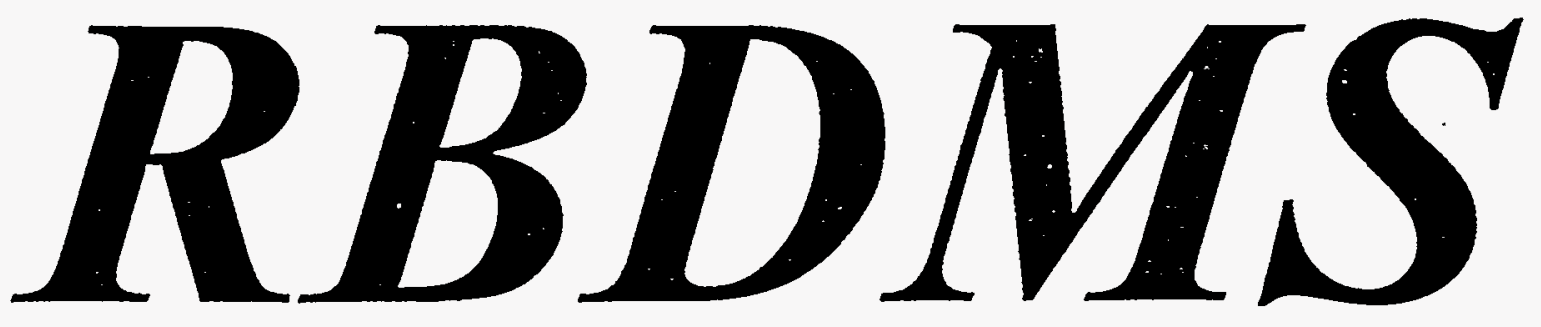

Risk Based Data Management System Administrators Guide

Version 4.0

Manual for

the Alaska Oil \& Gas Conservation Commission; the Mississippi State Oil \& Gas Board; the Montana Board of Oil \& Gas Conservation; and the Nebraska Oil \& Gas Conservation Commission.

Prepared for

The Underground Injection Practices

Research Foundation of the GWPC

Prepared by

CH2M Hill, Inc.;

Digital Design Group, Inc.; and

Virtual Engineering Solutions, Inc.

April 1995 


\section{RBDMS Hardware and Software Requirements}

The following tables detail the minimum and recommended hardware and software requirements to operate RBDMS.

\section{Hardware Configuration}

\begin{tabular}{|l|l|}
\hline Minmum & Recommended \\
\hline 80386 PC & 80486 or Pentium PC \\
\hline $6 \mathrm{Mb}$ RAM & $8+$ Mb RAM \\
\hline VGA Monitor & Super VGA Monitor \\
\hline 120 Mb Hard Disk & $\begin{array}{l}\text { Access compatible LAN with } 500 \mathrm{Mb}+\text { disk space } \\
\text { available }\end{array}$ \\
\hline HP III Laser Printer & Postscript Laser Printer \\
\hline
\end{tabular}

${ }^{1}$ For multiple user access to the database.

Software Requirements

\begin{tabular}{|l|}
\hline DOS $5.0+$ \\
\hline Windows 3.1 \\
\hline Microsoft Access 2.0 \\
\hline
\end{tabular}

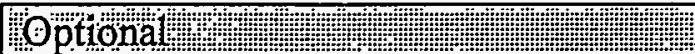

Microsoft Visual Basic version 3.0

Windows 3.11 or Windows NT

Version 3.5

Microsoft Excel Version 5.0

Microsoft Word Version 6.0

Wellbore

\section{Installing RBDMS}

The RBDMS installation is from two 3.5" high density diskette. The diskettes contain two Access MDB files (RBDMS.MDB and RBDMSDTA.MDB) and some other supporting files, in compressed installation files. The disk has an installation program to setup the software which is automatic: Please perform the following steps to install the RBDMS program:

1. Ensure that you have at least $6 \mathrm{Mb}$ disk space available

2. Insert the RBDMS, DISK \#1 into a diskette drive

3. Choose "File/Run" from Program Manager main menu and if the diskette is inserted in drive A: then enter the following A:SETUP <enter> or run the SETUP.EXE from the File Manager.

4. This will start a standard Window Setup program and install the files from the floppies to the hard disk. 
After creating the groups, create the users who will use RBDMS. To create new users perform the following steps:

1. Choose Security/Users from the Access default menu.

2. Click the "New" button.

3. Enter the new user name and personal $\mathrm{ID}$.

4. Click "OK"

5. Add the user to the appropriate group(s) by selecting the group and clicking "Add $>>$ ".

6. Click "OK" when all of the groups have been added to the "Member of:" list.

Users that are members of the RBDMS_READ group will only be able to use the "Inquiry" mode. They will not be able to edit or add new data to the database. Members of RBDMS_ALL will be able to update and add new data to all tables in RBDMS.

The administrator can create additional groups with security privileges specific to the groups needs. For instance the administrator could create a group called "RBDMS_MONITOR". This group might have rights to edit and create records in the Monitor table but read-only access to other tables.

User and Group information for Access is normally stored in a file called SYSTEM.MDA. If you have a PC network and have installed Access on each PC's local disk then each PC will have its own SYSTEM.MDA file stored in the local Access directory. In order to simplify administration of users and groups it is recommended that you change each PC's system database setting to use a common SYSTEM.MDA file shared on the network. You can change the SYSTEM.MDA setting using the Workgroup Admin (WRKGADM.EXE) program or editing the MSACC20.INI file and changing the . SystemDB setting.

\section{Table Relationships}

The graphic displayed below is a snapshot of the Access Relationship Editor Screen. The lines between fields in the tables represent table relations. If you need to temporarily disable a referential integrity check perform the following steps.

- Open the RBDMSDTA.MDB database with Access.

- Choose Edit/Relations from the Access menu.

- Double Click the line representing the relationship between to tables.

- Remove the check from the Enforce Referential Integrity check box.

- Close Referential Integrity Editor (save changes) and open RBDMSDTA.MDB. 


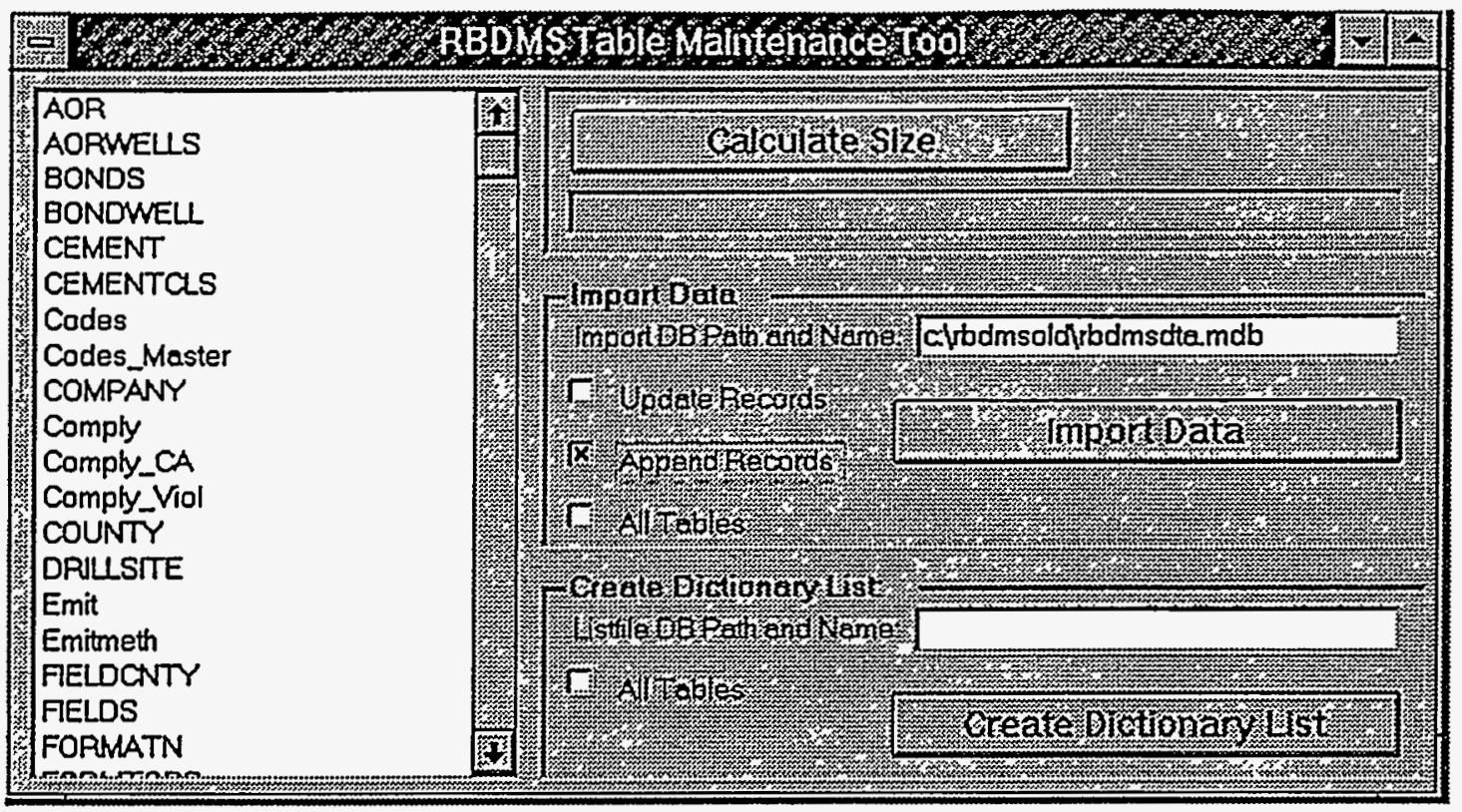

5. Enter the path to the previous version RBDMSDTA.MDB file (e.g. c:Irbdmsold lrbdmsdta.mdb)

6. Check the boxes for "Append Records" and "All Tables". "Update Records" should not be checked.

Click the "Import Data" button. The program will begin importing data. The import could take several hours for large databases.

\section{Building Practice Databases}

A "practice" RBDMSDTA.MDB is useful for training new users, testing update and append queries or evaluating new or modified reports and forms using data with known results. Several macros exist in the RBDMSDTAMDB database to assist in creating and maintaining a practice database.

The "mcrBuildRandomData" macro will create random EMIT, IMIT, UIC Permit and other records associated with each of the records in the WELL table. Create some records in the WELL table before you run this macro or it will not do anything.

The "mcrDeleteAllRecords" macro deletes all records from all tables in RBDMSDTA.MDB. The "mcrDeleteAllRecordsExceptWell" macro deletes all records except for the WELL table records.

The administrator should delete all three of these macros from the production database for security.

\section{Attaching Tables in RBDMSDTA.MDB}

RBDMS uses two Access "MDB" databases to store its objects. All of the table objects are stored in the RBDMSDTAMDB. All other objects such as forms, queries, macros, 
RBDMS implementation plan. Try to breakup the implementation into smaller more manageable tasks. Some suggested startup tasks are as follows:

- Codes - Update the Codes Tables with your state's OGCC districts and inspector names.

- Company - Update the Company Table with the names and addresses of operators and other companies doing business with your agency.

- County - Update the County Table with your state's counties.

- Pool - Update the Pool table with information on the Pools/Reservoirs in your state. This task is dependent on completion of the following two tasks:

- Formatn - Update the Geologic Formations Table (FORMATN) with the formations found in your state.

- Fields - Update the Oil and Gas Fields Table (FIELDS) with information on the fields in your state.

All of the above tasks (except "Pool") do not depend on other tasks to be performed and can be updated independently. It is not necessary to populate all fields in each of the tables. Some database fields may be updated later or may not be needed at all for your state. All of the tables listed above need not be populated if you do not intend to use the corresponding field(s) in the Well Table. For example the Pool table can be left empty if the pool numbers will not be entered into the Well Table. Please refer to the Table Relationships topic for a graphic of table relationships and referential integrity checks. A graphical representation of these tasks is presented below.

RBDMS

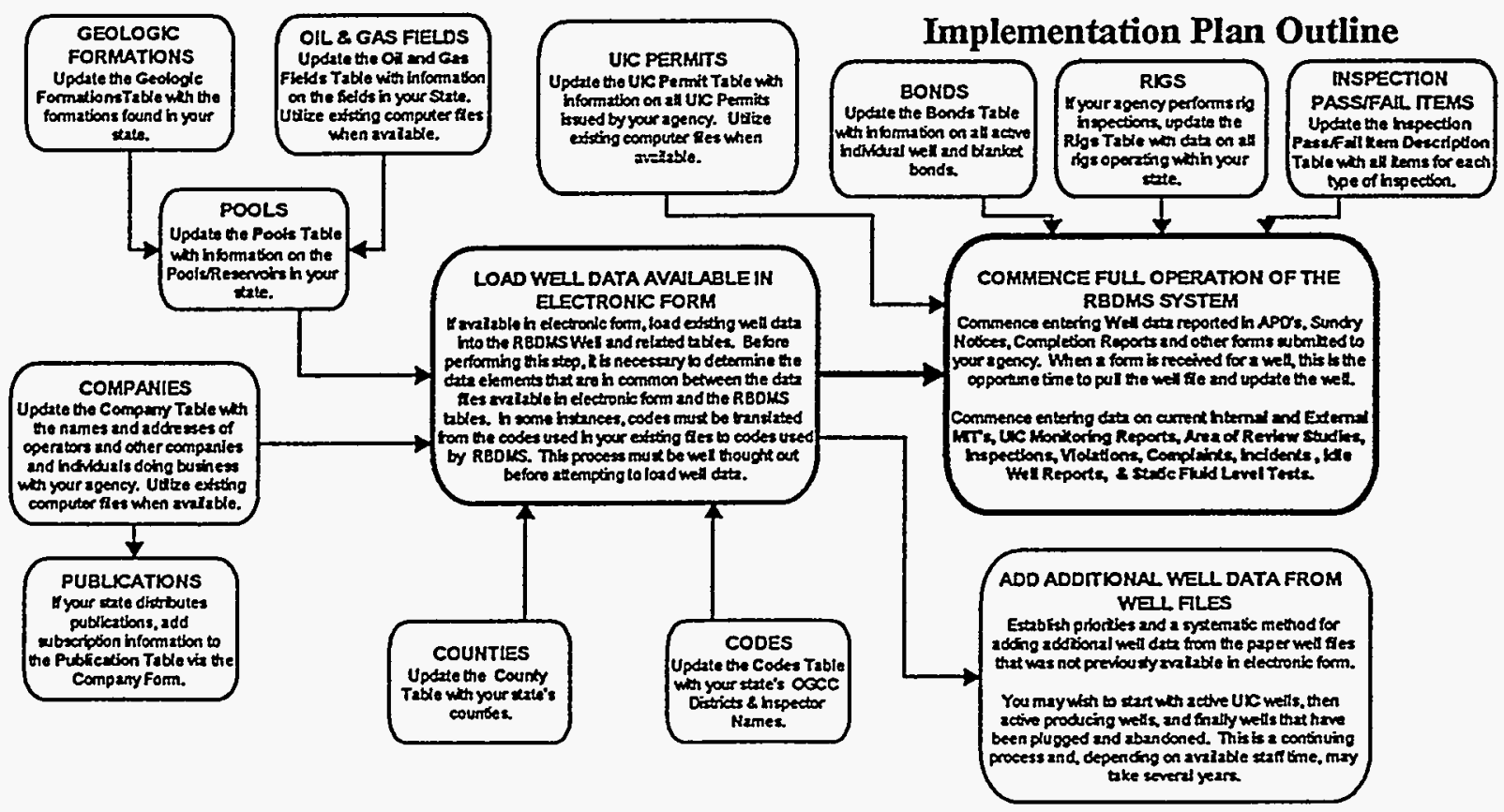


- Maintain multiple backup copies and implement a tape rotation system.

- Keep at least one recent backup at an offsite location.

- Backups should be stored in secure location(s).

- Restore procedures should be tested periodically.

After many updates and deletions the database will become fragmented and not make the best use of disk space. To correct this the MDB files (particularly the RBDMSDTAMDB file) should be periodically compacted. Before compacting the database make sure that no one is accessing the file and that you have adequate disk space for the original and compacted versions of the database. When you compact the file use "RDMSDTA.MDB" for the new database name. Access will create a temporary file while building the compacted database and will delete the old $\mathrm{MDB}$ and rename the new one when completed.

If a system crashes or loses power before exiting Access you may need to repair your $\mathrm{MDB}$ file(s). Please refer to the Microsoft Access User's Guide (page 628) for instructions on recovering a damaged database.

\section{Enhancing Performance}

The performance of RBDMS is dependent on the software and hardware environment that it operates under. Microsoft makes the following recommendations for optimizing Access 2.0 performance:

* Note that the optimal setting for each item may vary with the type of computer on which you run Microsoft Access. It is usually best to change only one setting at a time and then monitor database performance for improvement.

To optimize the general performance of Microsoft Access version 2.0:

1. Use the Add-in Manager to uninstall library databases that contain Microsoft Access Wizards, builders, and other add-ins you do not want. This reduces Microsoft Access memory consumption and load time.

2. Make more memory available by closing applications and terminate-and-stay-resident (TSR) programs that you are not using. Usually, these applications are loaded from the AUTOEXEC.BAT and CONFIG.SYS files.

3. Make sure your Microsoft Windows virtual memory (swap file) setting is large enough, and set to "permanent" rather than "temporary" memory. In general, the virtual memory setting plus available RAM should be no less than $25 \mathrm{MB}$. It should be more if you will be running several memory-intensive applications simultaneously. To check or change the virtual memory setting, start Microsoft Windows Control Panel. Double-click the 386 Enhanced icon, then choose Virtual Memory. To change the setting, choose Change. Make sure to select "Permanent" in the Type box. Choose OK 
VGA display, this can free about 256K of RAM. For a $1024 \times 768$ pixel display with 256 colors, this can free about 750K of RAM. (Your actual RAM savings depends on your video display.)

\section{Installing the First Class Bulletin Board Software}

To install the First Class software please perform the following steps from within Windows:

1. Insert the First Class installation disk in the A: drive.

2. From the Program Manager menu choose File/Run and enter "A:SETUP" for the program to run.

3. Install First Class in C:LFCWIN or choose another directory and modify the remaining instructions accordingly.

4. After First Class installation is complete, copy A:CH2MODEM.FCS to C:IFCWINISETTINGSICH2MODEM.FCS

5. Modify the First Class item in Program Manager by clicking once on the item and choosing File/Properties from the menu. Enter "C:LFCWINLFCCLIENT.EXE c:lfcwinlsettingslch2modem.fcs" as the command line for the program.

6. Configure your modem by selecting Service/Connection Setup/Modem from the First Class menu.

To use First Class double click the First Class icon and enter your user name (usually the first letter of your first name and your last name e.g. "BClinton") and your password

\section{RBDMS Object Naning Standards}

The RBDMS development team has adopted the Hungarian notation system recommended by Microsoft. The Hungarian notation system uses prefix and suffix codes on object names to identify object characteristics, for instance all form names should be prefixed with "frm".

Some RBDMS objects were created in Access before the adoption of Hungarian notation and were "grandfathered" in.

The following is a list of common prefixes:

- tbl - Table

- frm - Form

- qry - Select Query

- qrya - Append Query

- $\quad$ qryd - Delete Query

- qryu - Update Query 


\section{APPENDIX C}

\section{Technical Criteria for an Area-of-Review Variance Methodology}

- Table of Contents

-Executive Summary 


\section{CONTENTS}

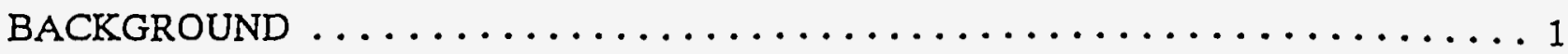

INTRODUCTION $\ldots \ldots \ldots \ldots \ldots \ldots \ldots \ldots \ldots \ldots \ldots \ldots \ldots \ldots \ldots \ldots \ldots$

EARLY STATE ACTIONS $\ldots \ldots \ldots \ldots \ldots \ldots \ldots \ldots \ldots \ldots \ldots \ldots \ldots \ldots$

TECHNICAL CRITERIA USED FOR JUSTIFICATION OF VARIANCE AREAS . . . . 10

Present Requirement for AOR Studies . . . . . . . . . . . . . . . . 11

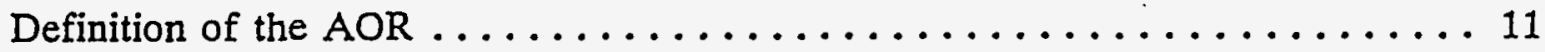

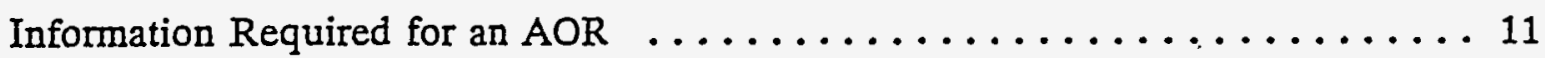

Variance Concept and Variance Criteria ..................... 12

AOR Variance Methodology ......................... 13

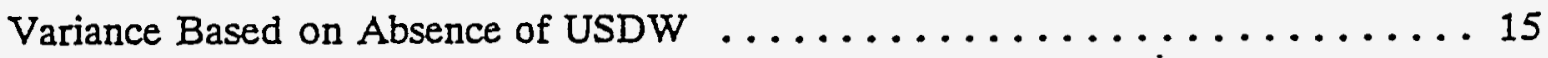

Variance Based on Lack of Intersection . . . . . . . . . . . . . . . 15

Variance Based on Negative Flow Potential . . . . . . . . . . . . . 15

USDW and Petroleum Reservoir Potentiometric Heads . . . . . . . . . 16

Procedure for Estimating Flow Potential . . . . . . . . . . . . 16

Effect of Combined Injection and Production Operations $\ldots \ldots \ldots \ldots$

Variance Based on Mitigating Geological Factors . . . . . . . . . . . . 17

Variance Based on Well Construction and Abandonment Methods . . . . . . . . 19

Development of Construction and Abandonment Standards . . . . . . . . 19

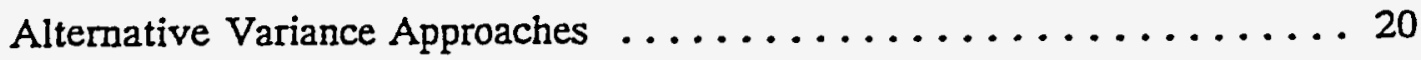

Sampling Wells for Evaluation ................ 23

Preparation of Wellbore Diagrams ............... 25

Tools Available for AOR Variance Evaluation . . . . . . . . . . . . . 27

Analysis of Well Construction and Abandonment

Evaluation Results .................. 33 
Variance Based on Other Compelling Evidence ................. 34

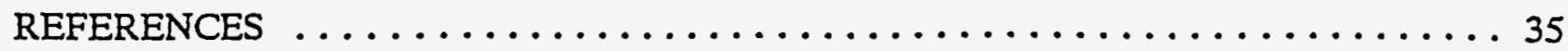

\section{APPENDICES}

Appendix A. The Underground Injection Practices Research Foundation Committee for the Development of a Model Variance Plan Guidance for the Use in the Area-ofReviews for Class II Injection Well Practices

Appendix B. EPA Underground Injection Control Permit Application and Instructions

Appendix C. Federal Advisory Committee: Final Document (March 23, 1992)

Appendix D. Discussion of Potential for Flow Upward from a Petroleum Reservoir Into a USDW

Appendix E. Idealized Step-by-Step Procedure for Evaluation of Flow Potential

Appendix F. Effect of Combined Injection and Production Operation

Appendix G. Sampling Wells for Evaluation of Well Construction and Abandonment Method

Appendix H. Wellbore Barrier Evaluation Program "ABE"

\section{TABLES}

Table 1. AOR Evaluation Methods, Information Required, Information

$$
\text { Sources and Available User Tools . . . . . . . . . . . . . } 30
$$

Table E-1. Spread Sheet Showing Data Used in Map Examples . . . . . . . . . . E-3

Table G-1. Sample Size Needed . . . . . . . . . . . . . . . . . . . . . G-9 
Table G-2. Probability that the Proportion of "Bad" Wells in the Population is $\leq 1 \%$ G-10

Table G-3. Probability that the Proportion of "Bad" Wells in the Population is $\leq 2 \%$ G-11

Table G-4. Probability that the Proportion of "Bad" Wells in the Population is 5 5\% G-12

FIGURES

Figure 1. Implementation of the Class II Injection Well Advisory Committee's

Recommendations for UIC Rule Revisions - Timeline for Direct

Implementation States . . . . . . . . . . . . . . . 5

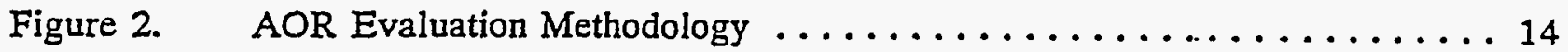

Figure 3. Sink, Squeeze and Sloughing Zone Rules $\ldots \ldots \ldots \ldots \ldots$

Figure 4. Example Well Construction Standards . . . . . . . . . . . . . . . 21

Figure 5. Example Well Abandonment Standards . . . . . . . . . . . . . . 22

Figure 6. Example Wellbore Drawing ................... 28

Figure D-1. Pressure $\left(\mathrm{H}_{\mathrm{p}}\right)$ and Evaluation $\left(\mathrm{H}_{2}\right)$ Head at Reference Point $\mathrm{A} \ldots \ldots$.... D-2

Figure D-2. Diagrammatic Drawing of Flow Potential Conditions in a

Petroleum Reservoir and Overlying USDW . . . . . . . . D-4

Figure D-3. Diagrammatic Drawing of Flow Potential Conditions in a

Petroleum Reservoir and Overlying USDW . . . . . . . . . D-5

Figure D-4. Diagrammatic Drawing of Flow Potential Conditions in a

Petroleum Reservoir and Overlying USDW ............ . D-6

Figure D-5 Diagrammatic Drawing of Flow Potential Conditions in a

Petroleum Reservoir and Overlying USDW ............ D-7

Figure D-6. Fresh Water Heads Calculated for Examples Shown in Figure

D-2 Through $\mathrm{D}-5 \ldots \ldots \ldots \ldots \ldots \ldots \ldots \ldots \ldots \ldots . \ldots \ldots$

Figure D-7. All Calculated Heads Calculated for Examples Shown in Figures

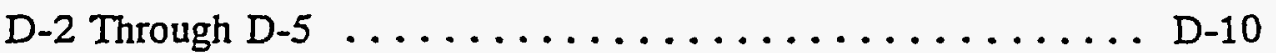

Figure D-8. Residuals Calculated for Examples Shown in Figures

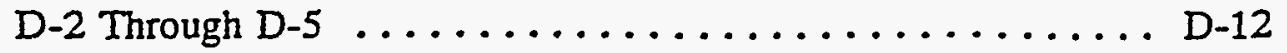

Figure E-1. Variance Example Map: Steps 1, 2 \& 3: Obtain, Post and Contour

USDW Head Data $\ldots \ldots \ldots \ldots \ldots \ldots \ldots \ldots \ldots \ldots \ldots$ 
Figure E-2. Variance Example Map: Steps 4, 5 \& 6 or Steps 7 \& 8: Obtain,

Post and Contour Reservoir Pressure Data . . . . . . . . . . . E-5

Figure E-3. Variance Example Map: Steps 9 \& 10 Using Fresh Water Gradient

Correction for Hydrocarbon Heads Above the Base of the USDW. E-6

Figure E-4. Variance Example Map: Steps 11, 12 \& 13 Using Heads

Adjusted to Fresh Water Equivalent Above the Base of the USDW E-7

Figure E-5. Variance Example Map: Residuals Corrected to Fresh Water

Head Equivalents Above the Base of the USDW .......... E-8

Figure E-6. Variance Example Map: Steps 9 \& 10 Repeated with Injection

Well Present ......................... E-9

Figure E-7. Variance Example Map: Steps 11, 12, \& 13 Repeated With Injection

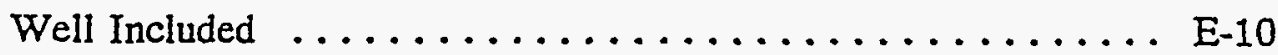

Figure E-8. Variance Example Map: Residuals Corrected to Fresh water Head

Equivalents Above the Base of the USDW ............ E-11

Figure F-1. Injection/Production Well Patterns Used in Enhanced

Petroleum Recovery Operations ................. F-3

Figure F-2. Equipressure Contours and Streamlines in a Five - Spot Pattern ... . . . F-4

Figure F-3. Analysis Requirements for Various Flow Potential Scenarios . . . . . . . F-6

Figure $\mathrm{H}-1$. ABE Program Evaluation Scheme . . . . . . . . . . . . . . . H-2

Figure H-2. ABE Program Logic for Abandoned Wells . . . . . . . . . . . . . H-5

Figure H-3. ABE Program Logic for Active Wells . . . . . . . . . . . . . . . . H-12

Figure H-4. Example \#1: ABE Evaluation for and Open Hole Abandoned Well .... H-17

Figure H-5. Example \#2: ABE Evaluation for an Open Hole Abandoned Well . . . . H-19

Figure H-6. Example \#1: ABE Evaluation for a Cased Hole Abandoned Well .... H-20

Figure H-7. Example \#2: ABE Evaluation for a Cased Hole Abandoned Well .... H-21

Figure H-8. Example ABE Evaluation for an Abandoned Well with Casing Pulled .. H-22

Figure H-9. Example ABE Evaluation for a Producing Well . . . . . . . . . . . H-23 


\section{EXECUTIVE SUMMARY}

This guidance was developed by the Underground Injection Practices Research Foundation to assist UIC Directors in implementing proposed changes to EPA's Class II Injection Well Regulations that will apply the Area-Of-Review (AOR) requirement to previously exempt wells. EPA plans to propose amendments this year consistent with the recommendations in the March 23, 1992, Final Document developed by the Class II Injection-Well Advisory Committee, that will require AORs to be performed on all Class II injection wells except those covered by previously conducted AORs and those located in areas that have been granted a variance. Variances may be granted if the Director determines that there is a sufficiently low risk of upward fluid movement from the injection zone that could endanger underground sources of drinking water.

This guidance contains suggested technical criteria for identifying areas eligible for an AOR variance. The suggested criteria were developed in consultation with interested States and representatives from EPA, industry and the academic community. Directors will have six months from the promulgation of the new regulations to provide EPA with either a schedule for performing AOR's within five years on all wells not covered by previously conducted AORs, or notice of their intent to establish a variance program. It is believed this document will provide valuable assistance to Directors who are considering whether to establish a variance program or have begun early preparations to develop such a program.

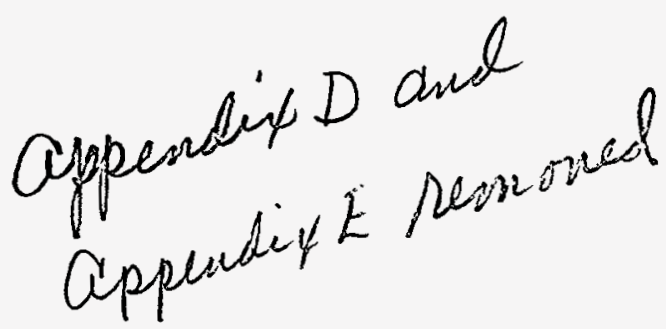

